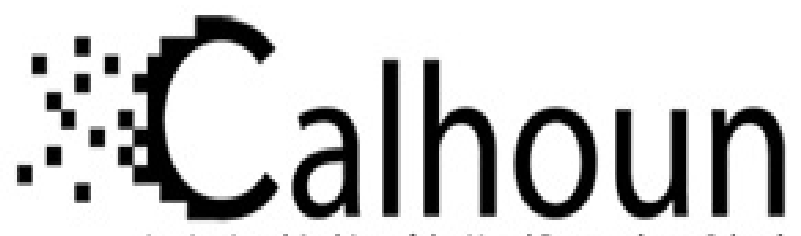

Institutional Archive of the Naval Postgraduate School

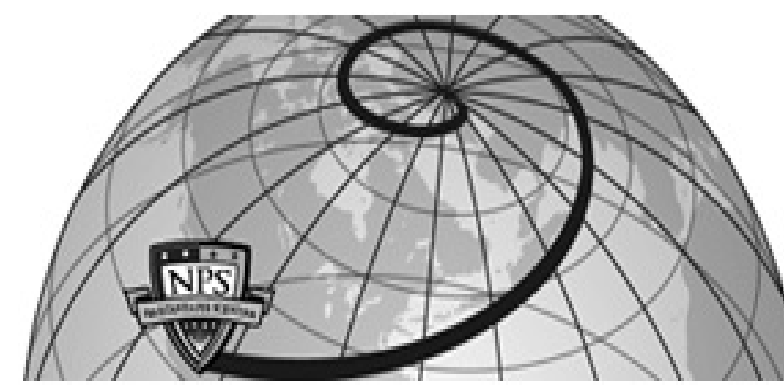

Calhoun: The NPS Institutional Archive DSpace Repository

Evaluation and Testing of the Solar Cell Measurement System Onboard the Naval Postgraduate School Satellite NPSAT1

Phelps, Ron; Michael, Sherif; Lo, Benson W.

Paper presented at the 22nd AIAA International Communications Satellite Systems Conference \& Exhibit 2004

https://hdl.handle.net/10945/30337

This publication is a work of the U.S. Government as defined in Title 17, United States Code, Section 101. Copyright protection is not available for this work in the United States.

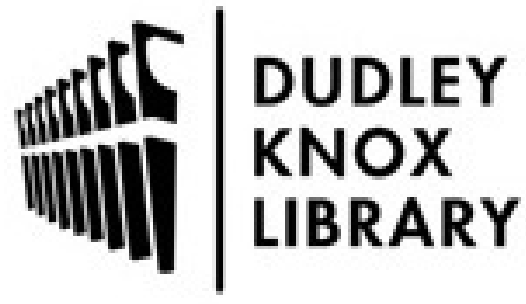

http://www.nps.edu/library
Calhoun is the Naval Postgraduate School's public access digital repository for research materials and institutional publications created by the NPS community. Calhoun is named for Professor of Mathematics Guy K. Calhoun, NPS's first appointed -- and published -- scholarly author.

Dudley Knox Library / Naval Postgraduate School 411 Dyer Road / 1 University Circle Monterey, California USA 93943 


\title{
Evaluation and Testing of the Solar Cell Measurement System Onboard the Naval Postgraduate School Satellite NPSAT1
}

\author{
Ensign Benson W. Lo, USNR* \\ Mr. Ron Phelps ${ }^{\dagger}$ \\ Dr. Sherif Michael \\ United States Naval Postgraduate School, Monterey, California 93943
}

\begin{abstract}
The Naval Postgraduate School Spacecraft Architecture and Technology Demonstration Satellite NPSAT1, launching in the fall of 2006, will include a system to measure the performance of new experimental triple junction solar cells. The measuring circuit used in the system is based on a circuit developed at NPS many years ago. The Solar Cell Measurement System (SMS) will trace the cells' current-voltage (I-V) curves while in orbit. The System consists of a radiation-hardened microcontroller that uses a radiation-hardened FPGA to monitor a collection of sensors. A current sink circuit is used to measure the current and voltage on the test cells. A total of 24 cells on the satellite will be tested, 22 of which are the experimental cells, and 2 are dual junction cells serving as reference cells. Prior to launch, extensive testing is being performed on the system to ensure proper operation. This paper presents the mission information, system design, test setup, and test results of the SMS.
\end{abstract}

\section{Introduction}

$\mathrm{T}$ he United States Naval Postgraduate School (NPS) is located in Monterey, California. Since its beginnings in 1909 at the United States Naval Academy, it has served as the U.S. Navy's corporate graduate university. Now it educates officers from all Services and international military officers in 29 curriculums leading to master, engineer, and doctorate degrees. In response to increased focus in space systems by the Department of Defense (DoD), the Space Systems Academic Group (SSAG) was established at NPS in 1982. It is multidisciplinary group comprised of faculty members from eight academic departments. The Group provides guidance for the Space Systems Engineering and the Space Systems Operations curriculums at NPS, and oversees various space-related research projects. Its major goal is to pair ongoing research with the graduate education of military officer students.

The SSAG is now involved in the design and construction of its second satellite, NPSAT1. Its mission is to perform several experiments, one of which is the Solar Cell Measurement System (SMS). The SMS electronics will measure the performance of experimental solar cells while in space. A prototype of the measuring circuit has been built and is now undergoing ground testing.

The objective of the ground test is to ascertain the circuit will operate as expected when subjected to space conditions. Of interest is the performance of the circuit when the cell and circuit temperature is varied away from room temperature. The cells also will have varying sunlight incidence angles as the satellite orbits around the earth. We will observe whether the circuit will produce an accurate current-voltage curve for the solar cells when they are at an angle to the light source. To describe the performance of the prototype circuit, the results of the circuit will be compared to that of a standard and proven cell measurement device.

This paper presents the background of the mission and the results of the testing completed so far. An introduction of the NPSAT1 satellite is presented first, followed by a brief overview of solar cell operation. A description of the NPS Solar Simulation Laboratory and the test setup follows. The SMS is then presented in more detail before presenting the test procedures and results.

\footnotetext{
${ }^{*}$ U.S. Navy Master of Science Student, Department of Electrical and Computer Engineering, bwlo@nps.navy.mil

${ }^{\dagger}$ Electronics Engineer, Space Systems Academic Group, rphelps@nps.navy.mil

* Associate Professor, Department of Electrical and Computer Engineering, michael@nps.navy.mil
} 


\section{NPSAT1 Architecture and Mission}

The Naval Postgraduate School Spacecraft Architecture and Technology Demonstration Satellite, NPSAT1, is the second satellite to be built by NPS SSAG. Its first satellite, PANSAT, was successfully launched aboard the Shuttle Orbiter Discovery in October $1998^{1,2}$. PANSAT was developed mainly to benefit the officer students at NPS, providing valuable hands-on experience. As a result, over 50 Master's theses became part of PANSAT's legacy.

NPSAT1 will build on lessons learned from the PANSAT project. Like PANSAT, NPSAT1 will enhance the academic experience for the students. The satellite will host several experiments onboard. Many of the systems on the satellite are untested in space, and the mission will provide better knowledge in designing future systems to be used in space. The NPSAT1 mission, conceived and developed by NPS SSAG, is sponsored and executed by the DoD Space Test Program (SMC Det 12). NPSAT1 will be one of five satellites on mission STP-1 scheduled to launch on an Atlas V Evolved Expendable Launch Vehicle (EELV) in September $2006^{2}$.

\section{A. Spacecraft Architecture}

NPSAT1 is an $81.6 \mathrm{~kg}$, semi-cylindrical satellite with 12 sides, covered with solar cells on all sides ${ }^{1}$. The solar cell array is divided into three rings (each with 12 sides or "panels"): top, middle, and bottom ring. Antennas are mounted on both ends of the spacecraft to allow communication in the event that the nadir face is not pointing toward Earth. The satellite is three-axis stabilized, controlled by the NPSAT1 Attitude Control System (ACS). It will orbit at $560 \mathrm{~km}$ and $35.4^{\circ}$ inclination, providing about 16 orbits per day ${ }^{1,3}$. Readers interested in the onboard systems are invited to refer to Ref. 1 and 2 for a detailed description.

\section{B. Mission Experiments}

Experiments on the satellite include a Configurable Fault-Tolerant Processor (CFTP), a Visible Wavelength Imager (VISIM), the Naval Research Laboratory-sponsored CERTO experiment and Langmuir probe, and the Solar Cell Measurement System.

The purpose of the SMS is to record the characteristics of experimental solar cells on the satellite. One third of the satellite will be covered with experimental solar cells made by Boeing Spectrolab. This mission will provide our sponsors with results of their operation in a space environment. The SMS will be discussed in detail later in this paper.

\section{Background on Solar Cell Properties}

While a detailed discussion on photovoltaic physics would be beyond the scope of this paper, a brief overview of basic solar cell properties can help understand the mission of the NPSAT1 SMS.

Solar cells convert light energy into useful electrical energy. To put it simply, photons bombard the cell, hitting electrons within the cell and knocking it loose. If enough collisions occur and enough electrons are freed, an electrical current can flow. Materials used in fabrication of solar cells are carefully chosen to extract energy from different portions of the electromagnetic spectrum. Since we are using solar cells to convert sunlight, we are interested in the visible spectrum of approximately 400 to $700 \mathrm{~nm}$.

Original solar cells were made mostly of silicon. Recent research has led to multi-junction solar cells. These cells have improved energy conversion efficiency. Boeing Spectrolab manufactures triple-junction cells with efficiency greater than 28\%, shown in Figure 1 with the material used for each layer.

Solar cells are characterized by its current-voltage curve, or I-V curve. It is a plot of the output current versus its output voltage under illumination. The following electrical properties describe the cell's performance:

$$
\begin{array}{ll}
I_{s c} & \text { Short-circuit current } \\
V_{o c} & \text { Open-circuit voltage } \\
P_{\max } & \text { Maximum output power } \\
\eta & \text { Efficiency } \\
f f & \text { Fill factor - "squareness" of the curve }
\end{array}
$$

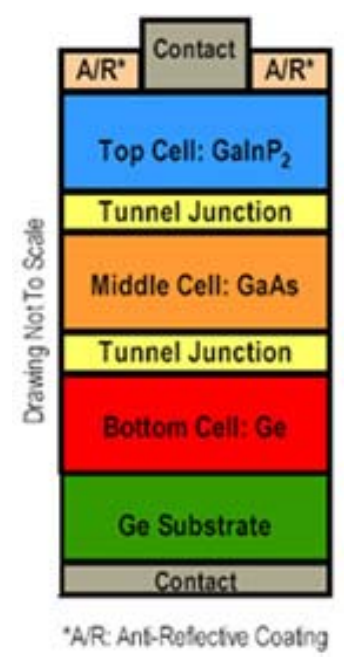

Figure 1. Triple junction solar cell, cross-sectional view $^{6}$ 
Figure 2 shows a sample I-V curve depicting the first three properties above. The fill factor $f f$ is found by

$$
f f=\frac{P_{\max }}{V_{o c} I_{s c}}
$$

The solar constant is defined as the amount of energy received on a unit surface perpendicular to the sunlight beams. In space, outside of the earth's atmosphere, the solar constant is about $1.353 \mathrm{~kW} / \mathrm{m}^{2}$ (Ref. 4,5). The cell efficiency $\eta$ is calculated as

$$
\eta=\frac{P_{o u t}}{P_{i n}}=\frac{P_{\max }}{C \times A},
$$

where

$C$ is the solar constant, and

$A$ is the area of receiving surface in square meters.

Another item important in understanding solar cell performance is the air mass number. The air mass number is defined to be the relative path length through the atmosphere ${ }^{4}$. For a path through the atmosphere that is perpendicular to the earth's surface (the shortest path from outer space to the earth surface), the air mass number is one, written and read "air mass one," or abbreviated as AM1. For other paths lengths at a zenith angle $z$, the air mass number $m$ is defined to be $m=\sec z$. Air mass numbers are often used to describe the solar spectrum at a particular location. Because in space the path length is zero, AM0 is often used to describe the solar spectrum in outer space.

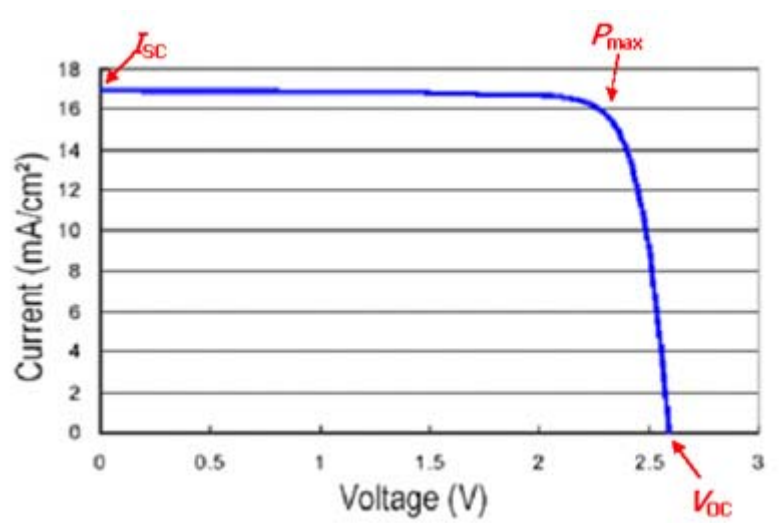

Figure 2. Sample I-V Curve (from a triple junction cell)

\section{NPS Solar Simulation Laboratory}

The Space Systems Academic Group's Solar Simulation Laboratory at NPS contains equipment for preflight performance testing of solar cells and the cell measurement circuit. The tests will reveal any potential problems with circuit design and give a good approximation for expected cell behavior in space. The main component of the Laboratory is the solar simulator.

\section{A. Solar Simulator}

The Solar Simulation Laboratory has an Optical Radiation Corporation Solar Simulator 1000 that uses a xenon arc lamp to provide light close to AM0 condition. The simulator outputs collimated light beams onto an area of about $8 \times 8$ inches, and it has adjustments to simulate light in AM1, AM1.5, and AM2 conditions. It is driven by a regulated power supply with adjustable current control, which controls the lamp's intensity.

The SSAG recently obtained a spectrometer to ensure the simulator is operating properly. The Ocean Optics HR2000 Spectrometer provides detection in the range of 200 to $1100 \mathrm{~nm}$. It connects to a computer via a Universal Serial Bus (USB) cable, and software interprets the data from the spectrometer and presents it to the user.

Figure 3 shows the measured spectrum of our solar simulator compared to the AM0 spectrum. It is important to understand that no artificial light can match AM0 exactly. Some of the spikes toward the higher wavelengths are expected, due in part to the weak response of the spectrometer at its operating wavelength limits where the device is prone to noise. However, since our tests are only to compare the SMS circuit against the HP6626A, for as long as both measurements were subjected to the same illumination, it does not matter whether or not the simulator spectrum is a perfect AM0. We will keep the spectrum to be as near AM0 as possible. 


\section{B. Measurement Equipment}

The solar cell under test is mounted on an aluminum mounting plate. Because the surface under illumination becomes hot, the cell temperature is controlled by a chilled water loop routed through the mounting plate. The water loop can maintain an illuminated plate temperature of about $15^{\circ} \mathrm{C}$ to above $40^{\circ} \mathrm{C}$, which is sufficient for our temperature tests.

The mounting plate contains probes to conduct current to and from the contacts of the solar cell. The probes are routed to the voltage/current measuring device. The plate is held on its longitudinal axis, allowing it to rotate. This rotation ability will be used in tests of various

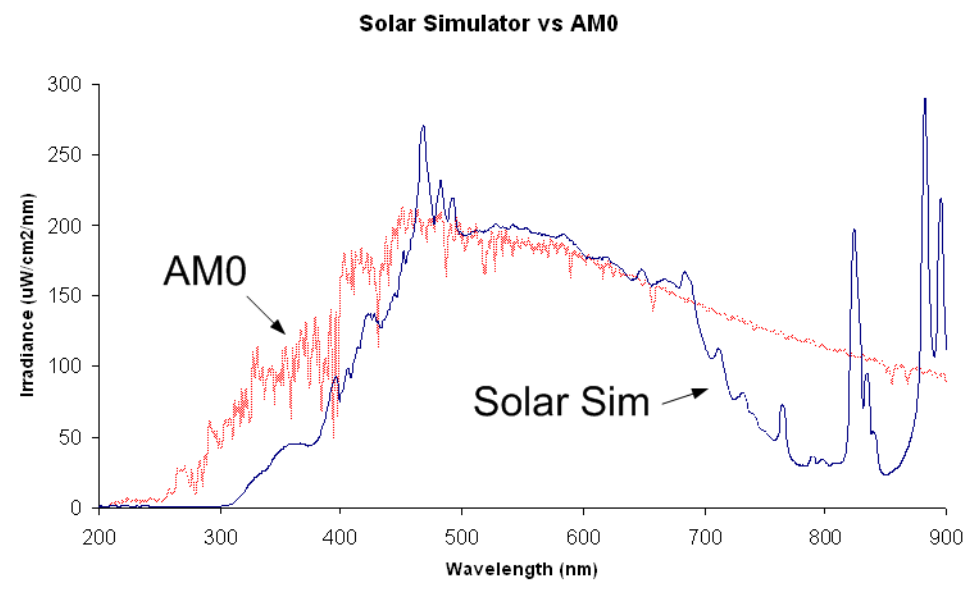

Figure 3. Solar Simulator and AM0 Spectrums. AM0 data from DoE/NREL/Wehrli 1985.

light-incidence angles on the cell. The measurement device for the experiment control is the Hewlett-Packard 6626A power supply (recent model is the Agilent 6626A power supply). The HP6626A acts as a traditional power supply and as a voltage and current sensor. It has the additional capability of being controlled by computer software through its IEEE-488 General Purpose Interface Bus (GPIB). For our tests, the HP6626A is controlled by a LabVIEW Virtual Instrument (VI) written specifically for cell tracing.

The power supply has four channels, and two of them are used for our solar cell measurements. Channels 1 and 2 are connected together in series, with Channel 1 acting as the sensing probe and Channel 2 set to bias the cell to $4 \mathrm{~V}$. The bias allows the power supply to better measure small voltage changes on the solar cell. Choosing $4 \mathrm{~V}$ is arbitrary; other reasonable bias voltage values can be used. In tracing an I-V curve, the computer directs Channel 1 to set a voltage, between $0 \mathrm{~V}$ and $V_{\text {oc }}$, on the test cell, and then senses the current through the cell. This is repeated for each desired voltage increment from a chosen starting voltage to the ending voltage. The power supply reports the voltage and current data back to the computer. Figure 4 shows the connection diagram with the cell and HP6626A. Note the polarities of the solar cell symbol; it is the opposite of what one normally sees for the diode.

Figure 5 shows the LabVIEW VI used to control the HP6626A for curve-tracing. The VI allows the user to input the starting and ending voltage to sweep, and a voltage increment. The graph preview area shows the collected data points after a sweep. The voltage-current data pair is recorded in an ASCII file specified by the user, and can be used later for plotting. The power supply sweeps the curve from $I_{s c}(0 \mathrm{~V})$ to $V_{o c}$.

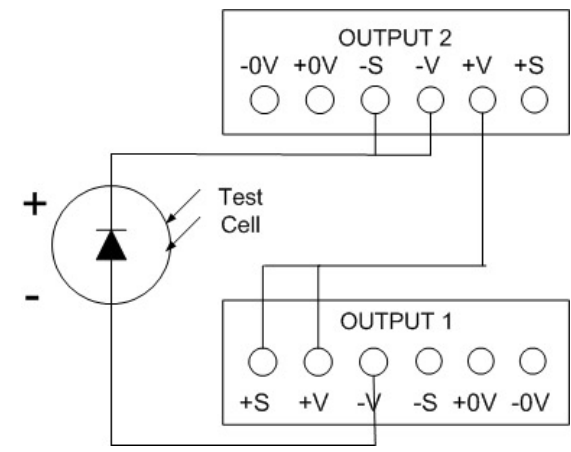

Figure 4. Connection diagram for the HP6626A Power Supply

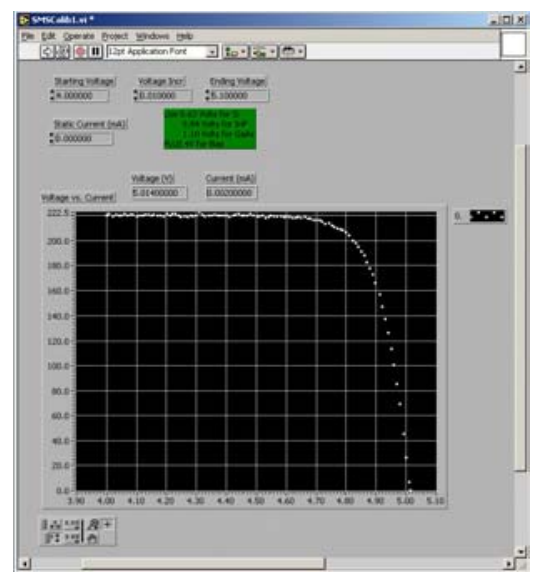

Figure 5. Virtual Instrument for HP6626A to trace I-V curves 


\section{The Solar Cell Measurement System}

Let us now examine the SMS in more detail. The SMS experiment on NPSAT1 will measure the characteristics and performance of the experimental triple-junction solar cells provided by Boeing Spectrolab. A total of 24 cells will be set aside to be used solely for the SMS experiment (i.e. not providing power to the satellite). Of these, 22 are the experimental cells, and two are commercially available dual junction cells used as the control cells. The characteristics of these dual junction cells are well documented.

The SMS experiment will also be an experiment of itself. The SMS is new to NPS. The preflight testing done here at NPS and described in this paper will reveal almost all potential problems, but it remains to be seen if all will be well when the satellite is in space.

\section{A. Background and Origins}

The idea of measuring the characteristics (I-V curve) of a solar cell sounds fairly simple. One may use a method like that described previously using a device similar to the HP6626A. To measure curves in space, however, is a little more challenging. A circuit had to be designed to do this measurement, and it had to be compatible with other systems onboard the satellite.

In 1986 at NPS, LT Robert Callaway, USN, and Professor Sherif Michael developed a novel circuit concept to trace an I-V curve 7 . This circuit is shown in Figure 6. It requires one operational amplifier (op amp) and one bipolar junction transistor (BJT).

The circuit is basically a current sink. It drives a desired current through the solar cell, and measuring the

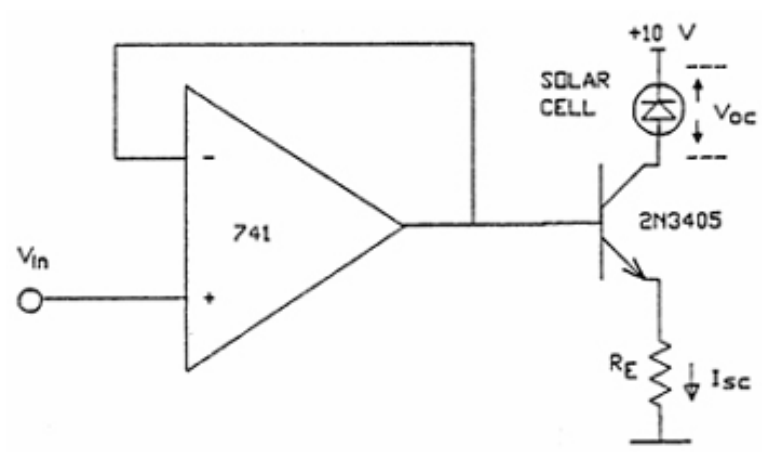

Figure 6. The Callaway current sink circuit ${ }^{7}$. voltage across the cell. This is repeated until enough data points are collected for an I-V curve. The op amp is configured as a voltage follower, placing $V_{i n}$ at the base of the BJT. The current through the cell (labeled $I_{s c}$ in the figure) is related to $V_{i n}$, with base-emitter voltage $V_{B E}$ and assuming the common-emitter current gain $\beta$ is large, by

$$
I_{S C}=\frac{V_{I N}-V_{B E}}{R_{E}}
$$

Using the Callaway circuit as the basis, Michael further improved it to use feedback in controlling the current. The Michael circuit, with minor updates in component technology serves as the basis for the SMS.

Ron Phelps and Capt. John Salmon, USMC, began work on the SMS to include the Michael circuit and a con-

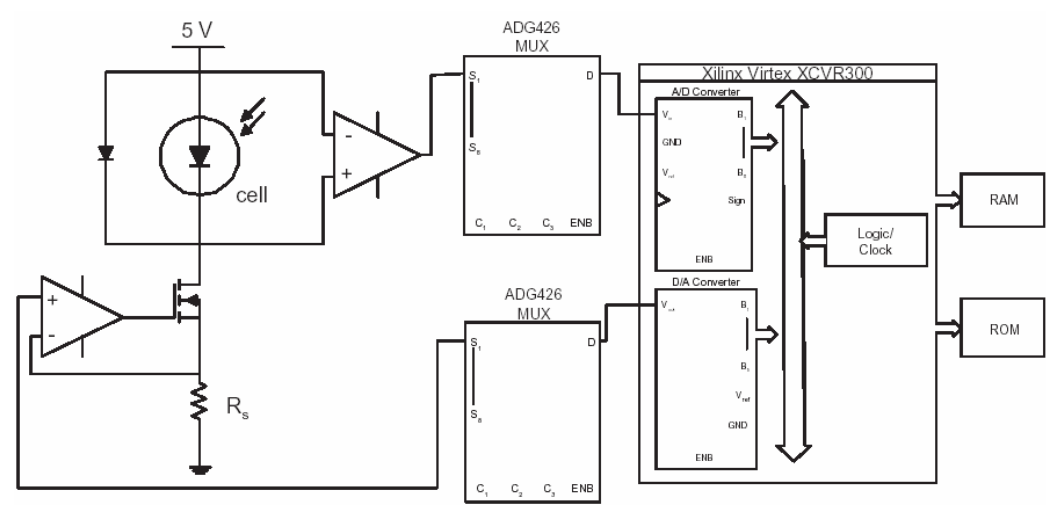

Figure 7. Simplified system diagram for the SMS for one solar cell. Left side is the analog subsystem, right side is the digital controller. troller. The design process is described in detail in Ref. 3. The SMS consists of two main parts: analog and digital. The digital subsystem is the system controller. It sets the voltage on the analog circuit to drive a desired current through the cell. It also takes the output of the analog circuit, which is the measured voltage across the solar cell, and stores it into memory. Figure 7 shows a simplified diagram of the SMS, in its entirety for one solar cell being tested. In comparison to the test setup in the Solar Simulation Lab, the digital system is like that of the computer and LabVIEW VI controlling the HP6626A power supply. 


\section{B. Analog Circuit Operation}

On the left side of Figure 7 is the analog subsystem. Currently, extensive testing is being performed on the ana$\log$ subsystem, the main focus of this paper. The digital subsystem is still under development.

Figure 8 shows, in more detail, the SMS analog circuit (from the Michael circuit) for one solar cell. The circuit uses an n-channel MOSFET and a feedback loop.

The circuit is also a current sink, and works similarly to the Callaway circuit. Setting a voltage $V_{\text {in }}$ pulls a current of $V_{i n} / R_{S}$ through the solar cell. In Figure 8, an input voltage is set on the non-inverting terminal of the OP497 op amp on the left. The initial (small) difference in voltage between the terminals is highly amplified and placed on the gate of the NMOS, turning on the transistor. A current starts to flow through the cell, NMOS, and resistor until the desired value of $V_{i n} / R_{S}$. The feedback loop ensures the flow of the desired current. An instrumentation amplifier (AD620B), with very high input impedance, is used to measure the voltage across the solar cell. With its gain set to unity, the output of the AD620B is simply the difference in voltage between the input terminals, which is the voltage across the solar cell. In the complete system, the output of the AD620B would be routed to the digital subsystem for analysis and storage.

A diode is placed across the solar cell as a measure of protection against reverse bias. In the unintentional case that more current is driven through the solar cell than the cell's $I_{\mathrm{SC}}$, a negative voltage will appear

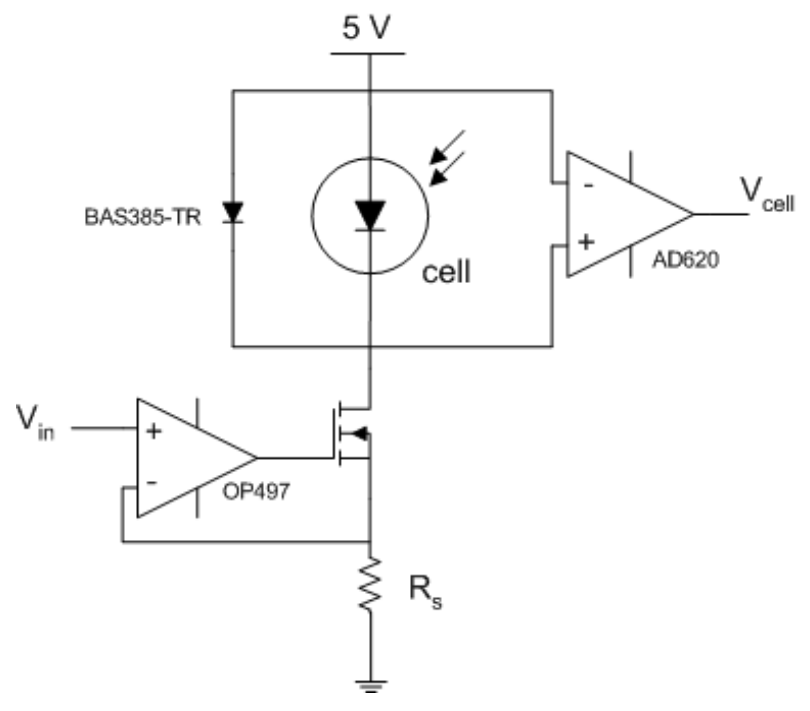

Figure 8. SMS analog circuit for one solar cell. across the cell, reverse biasing it. Reverse bias will cause irreparable damage on multi-junction solar cells.

For testing, a printed circuit board was made where it contains four of the SMS analog circuit, enabling it to have four cells connected at one time and taking their I-V curves. Each of the circuit has been labeled a channel. A LabVIEW VI was also written ${ }^{9}$ to control this circuit board.

On the satellite, the final system will have 24 channels, and therefore there will be 24 of the circuit in Figure 8 , one for each solar cell being measured. There will be one digital controller, and it will use multiplexers to choose from the 24 channels.

\section{Testing and Results}

Currently, the tests consist of doing the following:

- Vary the solar cell temperature (using $18^{\circ} \mathrm{C}, 28^{\circ} \mathrm{C}$, and $38^{\circ} \mathrm{C}$ ) and take $\mathrm{I}-\mathrm{V}$ curves using the SMS circuit. Compare the output with curves produced by the HP6626A at the same temperature.

- Vary the temperature of the SMS circuit board electronics and observe any differences in the output from that taken under room temperature.

- Vary the light incidence angle on the cell and take curves using the SMS circuit. Compare the output of each angle to the HP6626A output for that same angle.

- Perform multiple traces and observe its repeatability (to produce the same output). Also ensure all four channels on the test circuit board will output the same result for the same cell.

Figure 9 shows a plot of I-V curves taken by the SMS prototype circuit board of a $2 \mathrm{~cm} \times 2 \mathrm{~cm}$ triple junction cell under various light incidence angles at $28^{\circ} \mathrm{C}$. One may immediately notice a problem: the curve near the "knee" is noisy. After some troubleshooting, the source of the noise was traced to the data acquisition (DAQ) card that interfaces the circuit to the computer. We observed on the oscilloscope about $200 \mathrm{mV}$ (peak to peak) of noise came out 
of the DAQ. We are currently investigating a way to eliminate the output noise. We confirmed that it was not caused by the SMS circuit.

Although the curves were not perfect, we could still use them as a comparison. Comparing the 30-degree angle plot above to the 30-degree plot by the HP6626A (Figure 10), we noticed that while the curves matched perfectly past the $P_{\max }$ point, the $I_{s c}$ is lower for the SMS output. The same discrepancy resulted in data for other angles and temperatures. The suspicion rested on the noise from the DAQ, inhibiting an accurate measurement.

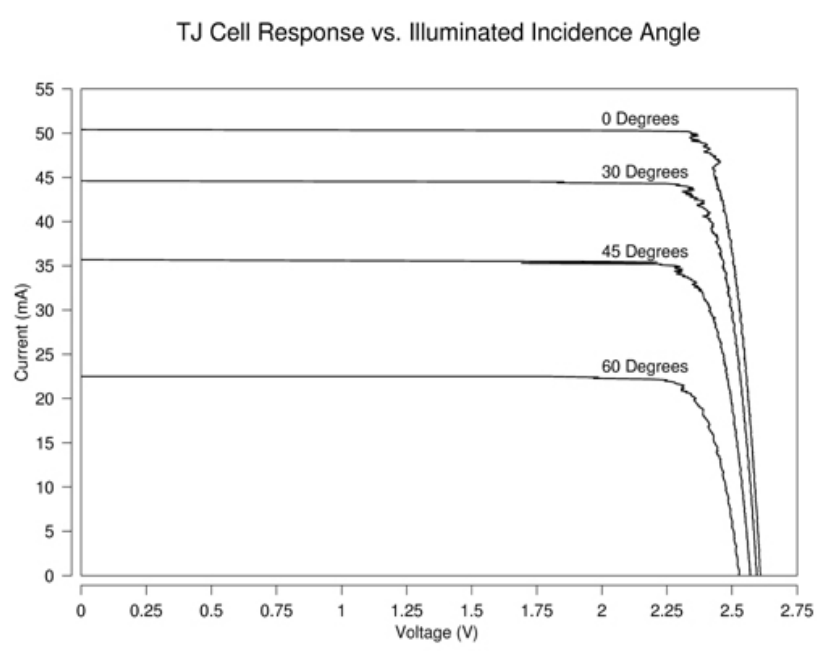

Figure 9. I-V curves of a $2 \times 2 \mathrm{~cm}$ triple junction cell with varying light incidence angles, taken by the SMS prototype circuit at $28^{\circ} \mathrm{C}$. The noise at the knee is due to the DAQ card, not the circuit.

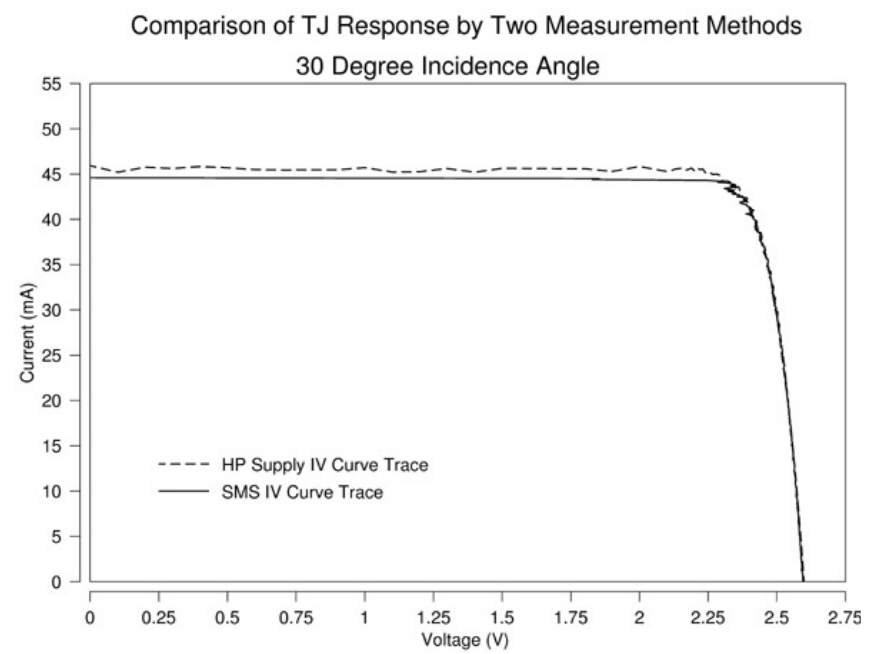

Figure 10. A comparison of the SMS trace against the control trace, taken at 30 -degree angle, $28^{\circ} \mathrm{C}$. The $I_{s c}$ for the SMS is lower than expected.

A manual sweep (i.e. not using the computer but rather using a variable power supply as input voltage and recording data points by hand) gave a slightly better result, shown in Figure 11. The manual sweep curve does not match the control curve to the right of the knee as well as before, and the cause of that will be investigated.

It is important to note that the circuit is designed to be current-controlled: the current is set, and then output voltage is measured. The LabVIEW VI for the circuit board was written to sweep from the $V_{o c}$ point to the $I_{s c}$ point. The curve is very flat from $I_{s c}$ to the top of the knee. A small increment in current around the top of the knee region will result in a large voltage drop very quickly. Thus, the output becomes very sensitive when the trace approaches the top of the knee. This sensitivity will affect the output voltage when there is noise, however slight, in the input. This does not occur in the control curve tracer, the HP6626A, because it sweeps the curve by setting the voltage across the cell (voltage-controlled). It steps through the voltage from zero to $V_{o c}$, and since the curve is not as close to vertical to the right of the knee as it is flat to the left of the knee, the tracing is not as sensitive.

The tests above used a commercially available triple junction solar cell. Tests are also being performed using the experimental cells to be used on the satellite to ensure the system also works for those cell technologies.

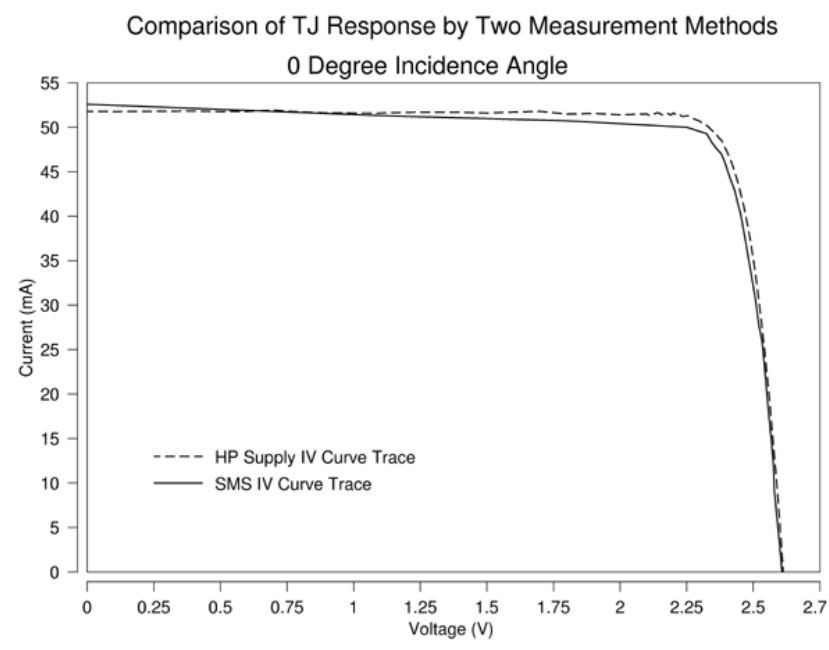

Figure 11. Comparison plot, this time the SMS circuit was controlled by hand (at $28^{\circ} \mathrm{C}$ ). 


\section{Conclusions}

We have described here only a part of the tests we are conducting. The temperature and repeatability tests are underway at the time of writing. Unfortunately, results of the tests are not yet ready. Based on the results we have gathered and presented here, more experiments will be conducted to fine-tune the circuit to produce more accurate results. From the tests already performed, however, we see that the concept works and has potential. We will continue to investigate the remedy to the sensitivity of the circuit at the flat region of the curve. We will also look into possibly developing a voltage-controlled circuit, where a voltage is applied across the cell while measuring the current, which is similar to how the HP6626A measures the cell.

\section{Acknowledgements}

We would like to thank the United States Navy, United States Air Force and DoD Space Test Program, Aerospace Corporation, Ocean Optics, Boeing Spectrolab, National Instruments, Xilinx, Cadence, Synplicity, and MathWorks for their support in this project.

\section{References}

${ }^{1}$ Horning, J.A., and Sakoda, D., "Overview of the NPS Spacecraft Architecture and Technology Demonstration Satellite, NPSAT1," Proceedings of the $16^{\text {th }}$ Annual AIAA/USU Conference on Small Satellites, SSC02-I-4, Logan, Utah, August 2002.

${ }^{2}$ Prater, G., Sakoda, D., and Grant, A., "Overview of the Naval Postgraduate School Small Satellite NPSAT1," $22^{\text {nd }}$ AIAA International Communications Satellite Systems Conference \& Exhibit 2004, Monterey, California, May 2004 (to be published).

${ }^{3}$ Salmon, J.B., et al, "Solar Cell Measurement System for NPS Spacecraft Architecture and Technology Demonstration Satellite, NPSAT1," Proceedings of the $17^{\text {th }}$ Annual AIAA/USU Conference on Small Satellites, SSC03-X-4, Logan, Utah, August 2003.

${ }^{4}$ Fahrenburch, A.L, and Bube, R.H., Fundamentals of Solar Cells - Photovoltaic Solar Energy Conversion. Academic Press, Inc., New York, 1983.

${ }^{5}$ Jet Propulsion Laboratory, "Solar Cell Array Design Handbook - Volume 1." National Aeronautics and Space Administration, 1976.

${ }^{6}$ Boeing Spectrolab, www.spectrolab.com, May 2004.

${ }^{7}$ Callaway, R.K., An Autonomous Circuit for the Measurement of Photovoltaic Devices Parameters, Master's Thesis, Department of Electrical and Computer Engineering, Naval Postgraduate School, Monterey, California, September 1986.

${ }^{8}$ Sedra, A.S., and Smith, K.C., Microelectronic Circuits, $4^{\text {th }}$ ed., Oxford University Press, New York, 1998

${ }^{9}$ Draper, M.B., and Stockton, H.E., Measuring the Degradation of Solar Cells Due to Exposure to Ion Engine Plasma Exhaust, Master's Thesis, Naval Postgraduate School, Monterey, California, September 2003. 